\title{
Mixed response to NIH's web journal plan
}

[PARIS \& WASHINGTON] A proposal by Harold Varmus, director of the US National Institutes of Health (NIH), for a global web site - E-Biomed - that would centralize much of the biomedical literature and make it freely accessible has met with a mixed reaction from publishers and scientists worldwide.

Under the proposal, articles could either be submitted for publication without refereeing — as e-prints — or after peer review by third-party 'editorial boards' (see Nature 398,735 ; 1999). The operation would be run by an independent governing body.

The goal of making the literature more readily available has been widely welcomed. But many are sceptical of the idea's desirability and feasibility. Some criticisms stem from a defence of vested interests or the status quo, while others reflect the uncertainties surrounding what is a preliminary proposal. In any case, Varmus has achieved one of the goals of the proposal: "to accelerate much-needed public discussion of electronic publication in the United States and abroad".

Axel Kahn, editor of Médecine et Sciences, the leading French-language biomedical journal, says the proposal challenges the "naked emperor" of scientific publishing - that " 80 to 90 per cent of what is published is of little real interest". Publish or perish "rather than intrinsic merit" has become "the principal justification for much of the output," he says.

Kahn claims that most journals are infrequently consulted, and that E-Biomed would "allow you to have access to the articles you want, without having to browse hundreds of journals". A shake-out of the journals system is long overdue, he says, adding that there is only a real need for the cream of journals, and in particular the best multidisciplinary journals.

Geert Noorman, managing director of Elsevier Science's Life Sciences Division, also says he welcomes the proposal. The exponential growth in scientific output means that "new ways of processing and organizing information are needed," he says. Noorman's comments surprise some observers, who predict that the big commercial publishers will mount a lobbying offensive to try to block public funding for E-Biomed.

One major concern is that the proposal could harm the best existing journals, without accelerating improvements that might gradually occur in any case as a result of market forces and more diffuse web efforts by

\section{EU warns on growth-hormone cancer risk}

[WASHINGTON] A growth-enhancing hormone fed to cattle "has to be considered as a complete carcinogen", based on a substantial body of recent evidence, according to a committee of the European Commission (EC) reporting on Monday (3 May).

The EC's Scientific Committee on Veterinary Measures issued its finding at a critical time - just ahead of the 13 May deadline set by the World Trade Organization for European Union compliance with the WTO's ruling of 1997 that the EU must accept hormone-raised beef for import. In that ruling, the WTO declared illegal a 1989 EU ban on imports of hormone-raised beef, saying that the EU had not conducted a proper risk assessment. The study was meant to address that concern.

The committee report - which is interim and open for public comment finds that $17 \beta$-oestradiol "exerts both tumour initiating and tumour promoting effects". The report is a risk analysis of residues in beef from six growth-promoting hormones fed to cattle. It found that, for all six hormones studied, endocrine, developmental, immunological, neurobiological, immunotoxic, tenotoxic and carcinogenic effects "could be envisaged", although such risks could not be quantified.
But the study drew fire in Washington, where some argued that it was a European ploy to avoid WTO sanctions if the EU fails to accept hormone-raised beef imports.

A State Department official calls the report's timing "highly suspect". "After all these tests over all these years [showing the safety of such beef] there is suddenly a dramatic new scientific discovery... What they are desperately trying to do is find some excuse [to avoid WTO sanctions]. It's transparent," says the official.

And an official at the US Food and Drug Administration dismisses the report as void of "new information". Bert Mitchell, acting deputy director of the agency's Center for Veterinary Medicine, says: "We have very carefully reviewed the safety of these hormones over several years. Our position is that they are safe."

But the report drew praise from consumer advocates. "This is going to be a good test of the ability of Europe to withstand the pressures of an unaccountable World Trade Organization," says Jeremy Rifkin, president of the Foundation on Economic Trends in Washington. "There are serious potential health risks that should be looked at. It's not resolved that this is safe. The burden should not be on the public to prove it's safe." not-for-profit science publishers. Several observers say it might create an unhealthy monopoly, erode the diversity of existing journals, and reduce competition between journals for the best papers.

The Varmus proposal notes that the current journal structure has served the biomedical community well for 300 years. "So the first question I ask is, if it has served us well for 300 years, why change?" says Martin Frank, executive director of the American Physiological Society, which publishes 14 journals and 36,000 pages of articles each year.

"It [E-Biomed] is extremely cumbersome and is not going to be easily implemented," says Frank. "It is so unclear in terms of process that it's going fall under its own weight."

Frank and other non-profit publishers are irritated at what they claim has been their omission from early discussions of the proposal, even though it intimately affects them. Thirty non-profit publishers wrote to Varmus on 29 March, as word of the proposal began to spread, asking him for a meeting to discuss the plan.Varmus points out that a series of meetings is being scheduled with organizations worldwide such as the European Molecular Biology Laboratory (see box opposite), but that these will take some time to arrange and conduct. He also intends to post the proposal on his NIH web page for comment.

Some observers note that the page charges collected by some publishers provide them with a cash cow - and that in the United States the NIH is one of the largest that is milked. Under the existing system, page charges can be passed on to the biomedical agency by investigators that it supports. The potential loss of this lucrative system is alarming publishers - especially non-profit organizations - which rely heavily on it.

Proposals that E-Biomed should coordinate peer review of its contents are controversial. Noorman argues that centralization of peer review would threaten the diversity of schools of thought provided for by journals.

This concern is shared by many scientists and learned societies, who feel that a centralized structure may obscure the well-defined hierarchy of best science provided by journals, and that scientists may be more reluctant to give their time and energy free to a central structure.

Andrew Odlysko, a mathematician at the AT\&T telecoms corporation and an expert on scholarly publishing, argues that it would be simpler to separate the distribution and peer-review functions of the repository, as is done at the Los Alamos physics e-print servers, where peer review is provided by journal 'overlays' to unrefereed papers.

Lynn Dobrunz, a postdoctoral neurobiologist at the Salk Institute in San Diego, asks: "Would E-biomed be in addition to the 
current system of journals, or instead of it? If there was a consolidated site that published online versions of all the articles that are currently published... that would be fantastic. If it's instead of, and especially if it has this nonpeer-reviewed track to it, I think that is a much less good idea."

The Varmus proposal suggests that scientific societies could be one source of peer review. But the societies are worried that $\mathrm{E}$ Biomed may undermine the journal revenues on which many of their other activities, such as fellowships and meetings, depend.

The head of one society says he is open to change, but would need guarantees that revenues would be preserved. Given such guarantees, societies might consider joining the initiative, he says. "E-Biomed will only fly if learned societies and their journals can be brought to the table," predicts Tony Delamothe, web editor of the British Medical Journal, and a supporter of E-Biomed's goals.

Another broader threat, expressed by many scientists, is that NIH might come to dominate much of the biomedical literature, leading to homogenization or to discrimination against scientists from smaller countries. "Who would select the governing body?" asks an official at one European scientific society. "Who would select the editors and decide what is allowed to be published? Who will determine costs and access rights?"

Many are also uncomfortable with the prospect of public funding for scientific publishing, an activity currently dominated by for-profit and non-profit publishers in the private sector. At the same time, however, there is growing resentment among scientists and librarians at the spiralling inflation in journal subscriptions.

Competition between scientific publishers is less than in other industries because of distortions in the market, and profit margins as high as 40 per cent are not uncommon (see Nature 397, 195-200; 1999).

Graham Cameron, head of services at the European Bioinformatics Institute (EBI) in Cambridge, England - an outstation of the European Molecular Biology Laboratory points out that public domain databases such as PubMed and GenBank and the EBI are widely considered to provide high levels of cost-effective service to the community.
Many believe, however, that the wider and cheaper access promised by E-Biomed may happen anyway as a result of market forces. "Most scientific society publishers are already doing what Varmus is proposing," says Frank. "We are putting our journals on the web. We are linking our journals through PubMed to our sister journals on the web. We are developing interfaces for the submission and review of manuscripts on the web." Similarly, consortia of library and other users are increasingly negotiating electronic licences for journals for entire institutions and even countries. Scientists at such institutions can already access much of the literature online.

"My initial reaction to E-Biomed is, 'so what?'. Virtually every library has almost all major journals," says Heinz Steiner, a neuroscientist at the University of Tennessee College of Medicine in Memphis.

Market forces are also driving a flurry of deals among publishers that may enable researchers to move rapidly and seamlessly from a citation to full text across journal boundaries.

Frank asserts, for example, that the web site of HighWire Press already accounts for a large proportion of the biomedical literature. This not-for-profit outfit was set up in 1995 by Stanford University Libraries and Academic Information Resources to help universities and societies to publish on the web at low cost. "So I don't know why we need to create E-Biomed," says Frank.

Indeed, the head of one scientific society argues that resentment over the huge costs of the current journals system is confusing the many complex issues involved in scholarly publishing. "If publishers are charging too much then we should attack this problem directly, but not attack the entire system. EBiomed is a not very selective nuclear bomb."

Noorman, while admitting that Elsevier's profit margins "are higher than the average," says that the arrival of web publishing is putting pressure on commercial publishers. "Scholarly publishing will become a proper [not distorted] market," he predicts. "Elsevier is not in the world to keep that profit margin high. We are in the world to stay in the market. If the web causes us to have to agree to lower profit margins, then so be it." Declan Butler \& Meredith Wadman

\section{MBO seeks European role in E-Biomed}
[PARIS] Frank Gannon, executive director of the European Molecular Biology Organization (EMBO) in Heidelberg, will meet Harold Varmus next week to discuss possible European input into E-Biomed.
"Europe has to be intensively involved [in the
discussions]," says Gannon "I welcome the discussion that has been stimulated by the E-Biomed proposal," says Gannon. "It has brought [debate on electronic publishing] to a head."
Gannon, who shares many of the scientists

concerns about the proposal, says that "the European Bioinformatics Institute and EMBO are willing to play a part in seeing that there is a successful outcome.

"If it is going to happen, $\mathrm{EMBO}$ is uniquely placed to represent European interests." D. B.

\section{Automation 'could crack the big problems in science'}

[WASHINGTON] A new type of laboratory that would collect and analyse vast amounts of data to solve complex biological problems is being proposed by scientists from US universities and government laboratories.

The approach, called 'batch science', would use laboratory automation to address areas of research that its advocates say are being held back because existing laboratories lack the capacity to collect and analyse the necessary volumes of data.

They argue that existing biology laboratories in universities and government agencies are too small and labour-intensive to produce the experimental data to answer important scientific questions.

Questions suited to the approach include the characterization of pathogens carrying infectious diseases, so as to anticipate the mutation of virulent strains; rapid assessment of agents used in biowarfare or bioterrorism attacks; and the screening of food products to ensure food safety.

Last week in Washington, about 200 scientists from different disciplines met at the National Academy of Sciences to exchange ideas on laboratory automation and batch science. The meeting, "Automation in threat reduction and infectious disease research: need and new directions", was instigated by the University of California at Los Angeles and the Los Alamos National Laboratory in New Mexico. It was also sponsored by the National Academy of Engineering, the Institute of Medicine and three government agencies.

Kumar Patel, a physicist at the University of California and former president of the American Physical Society, who helped to organize the meeting, says the government tends to support traditional models of 'small' or 'big' science, but should be persuaded to build the highly automated, medium-sized laboratories that could do batch science.

While pharmaceutical companies have been using such approaches for drug development, and genome sequencers are engaged in the automated mass production of sequencing data, government agencies and universities analyse samples manually and on a small scale. Agencies such as the Centers for Disease Control and Prevention, which exists to protect the country from infectious disease, have little or no capability for the large-scale processing of samples. Some scientists argue that such a capability, combined with computer analysis of the results, could enable the agencies to function far more effectively.

Patel said people at the meeting "had generally agreed that having such an automated scheme might go a long way toward filling the holes" in these disciplines. Colin Macilwain 